\title{
Vinagreira: novo hospedeiro de Corynespora cassiicola no Pará
}

Tathianne Pastana de Sousa Poltronieri ${ }^{1}$; Luiz Sebastião Poltronieri²; Jaqueline Rosemeire Verzignassi ${ }^{3}$, Ruth Linda Benchimol'; Eudes de Arruda Carvalho $^{2}$

${ }^{1}$ Departamento de Fitopatologia e Entomologia, Instituto de Biologia, Universidade Federal Rural do Rio de Janeiro, CEP 23890-000, Rio de Janeiro, RJ. ${ }^{2}$ Embrapa Amazônia Oriental, Tv. Enéas Pinheiro, S/N, CEP 66095-100, Belém, PA.; ${ }^{3}$ Embrapa Gado de Corte, Rodovia BR 262, km 4, CEP 79002-970, Campo Grande, MS.

Autor para correspondência: Jaqueline Rosemeire Verzignassi (jaqueline@enpgc.embrapa.br)

Data de chegada: 09/11/2011. Aceito para publicação em: 13/02/2012.

A planta de Hibiscus sabdariffa L., da família Malvaceae, de nome popular vinagreira, tem origem controversa, África ou Ásia, sendo posteriormente levada aos países da América Central e do Sul. A espécie apresenta diversas sinonímias como, por exemplo, rosela, azedinha, azeda-da-guiné, pampulha, papoula, quiabo-deangola e quiabo-róseo. A planta é cultivada em regiões tropicais e subtropicais do mundo, ocorrendo em até $900 \mathrm{~m}$ de altitude, bem adaptada em regiões com distribuição de chuvas entre 800 e $1600 \mathrm{~mm}$ e temperaturas variando de $18^{\circ}$ a $35^{\circ} \mathrm{C}$. H. sabdariffa é sensível ao fotoperíodo e é muito cultivada no Pará, sendo utilizada como hortaliça, medicinal, ornamental e têxtil. As folhas da planta são ricas em vitaminas $\mathrm{A}$ e B1, sais minerais e aminoácidos. A região nordeste do Brasil é a maior produtora e consumidora de folhas secas da vinagreira, para a utilização sob a forma de chá. Em áreas experimentais da Embrapa Amazônia Oriental, Belém, PA, plantas de vinagreira apresentaram alta incidência e severidade de doença caracterizada por pequenas lesões necróticas foliares de coloração escura no centro e halo amarelado. O fungo foi isolado em BDA (Batata-Dextrose-Ágar) e identificado, revelando a presença de Corynespora cassiicola (Berk. \& M.A. Curtis) C.T. Wei. As colônias do patógeno apresentaram coloração cinza, com micélio aéreo de aspecto aveludado e cotonoso. O patógeno produziu conidióforos eretos, ramificados, com até 20 septos, de coloração marrom, típicos de C. cassiicola. O fungo é o agente causal da mancha-alvo em várias espécies agrícolas, florestais e ornamentais importantes no Brasil e no mundo. C. cassiicola foi anteriormente relatado no estado do Pará causando mancha-alvo em juta (Corchorus capsularis L.), cacau (Theobroma cacao L.), tomate (Lycopersicon lycopersicum L.), pimenta longa (Piper hispidinervum C.), acerola (Malpighia sp. D.C). O teste de patogenicidade foi realizado por meio da deposição de discos de cultura nas faces adaxial e abaxial de folhas sadias e destacadas de vinagreira. As folhas inoculadas foram mantidas sob câmara úmida por 48 horas e, após esse período, foram mantidas em condições ambientais de laboratório. Os primeiros sintomas foram observados quatro dias após a inoculação e o reisolamento do patógeno foi efetuado a partir das lesões, confirmando C. cassiicola como agente causal da doença. Este é o primeiro relato do patógeno em plantas de vinagreira no Pará.

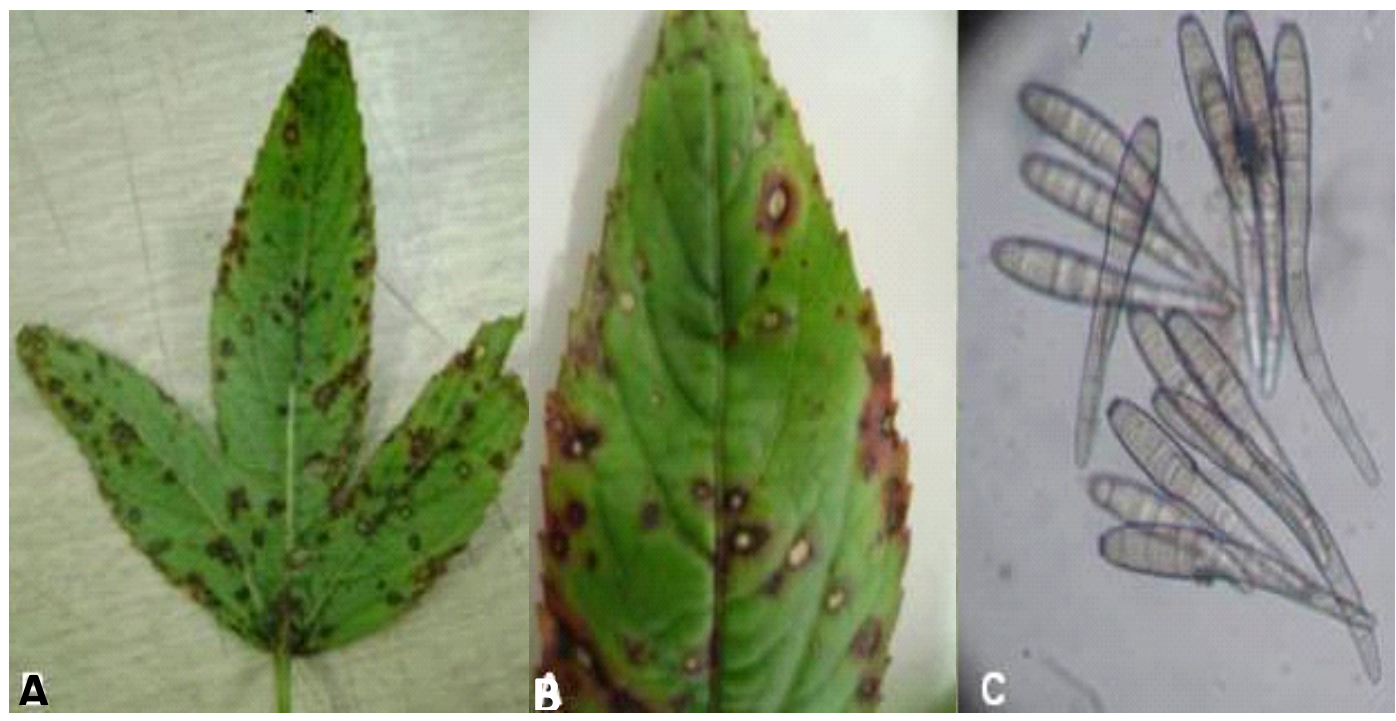

Figura 1. Sintomas de mancha-alvo em vinagreira causados por Corynespora cassiicola (A e B); conídios do patógeno sob microscópio óptico (C). 